\title{
VARIA
}

\author{
SANTIAGO VENCEDOR DE LOS MOROS. GUARDEME DEL ENEMIGO \\ Una rodela flamenca con leyenda en castellano, del s. XVI, en Praga
}

Recientemente, se produjo un hecho insólito, impensable hace diez años, al ofrecerse una Fundación checa —Hieronymus-, a cubrir los gastos de la restauración del Jardín de las Delicias, de El Bosco, en el Prado que se está llevando a cabo ${ }^{1}$. Los tiempos cambiantes ya son una realidad. En Praga, la Fundación Hieronymus hizo lo mismo con dos pinturas al margen de la obra del pintor flamenco. Con este motivo se celebraron ya dos exposiciones exclusivas dedicadas a dichos cuadros en la Galería Nacional de Praga y en el Museo Nacional de Praga, respectivamente. Sin embargo, aparte de las efímeras actividades aparecieron dos publicaciones, siendo la primera integrada en algún aspecto en la segunda ${ }^{2}$. El objeto de nuestra atención será el segundo cuadro que lleva una inscripción en español, por lo cual toca a España más inmediatamente que la primera obra El joven Jesús en el templo. Se trata de una rodela con una leyenda en castellano que dice SANTIAGO VENCEDOR DE LOS MOROS. GUARDEME DEL ENEMIGO (Fig. 1).

El Museo Nacional de Praga es, en realidad un Museo de Ciencias Naturales; sin embargo, cuenta con departamentos de Historia, Numismática, Arqueología y afines. Entre sus colecciones más variadas guarda objetos que salen a la luz de vez en cuando con no poca sorpresa, ante todo si se restaura algún objeto casi perdido en la memoria, una pieza guardada en las colecciones del Museo desde tiempos muy remotos. Tal ocurrió al restaurarse ${ }^{3}$ una rodela de apenas medio metro de diámetro. La rodela es de madera convexa, pintada, de tipo renacentista italiano, a juzgar por las analogías guardadas. Ésta no estaba destinada a batallas, sino que tenía simplemente una función decorativa ${ }^{4}$. Al limpiarse la superficie, se descubrió una imagen de primerísima calidad que representa un ejército de figuras bizarras y extrañas, encabezadas por un asno, rodeado todo del citado rótulo en español.

De la historia de la pieza sólo sabemos que fue regalada al Museo Nacional por Hugo Netwal en el año 1855. Últimamente fue identificada con el objeto registrado en el inventario de la

1 Ej.: «Češi financují obnovu Boschova obrazu» (Checos financian la renovación de un cuadro de El Bosco). Slovo (Praga), 28-11-1997.

2 Hieronymus Bosch-Follower, Christ among the Doctors. The painting after restoration. Olga Kotková, Editor. Praha 1966 (texto en checo e inglés) y luego Hommage à Bosch. Fundation Hieronymus. Praha 1997.

3 Debido a la contribución de la Fundación Hieronymus, dirigida por Bohumil Vurm. La restauración fue llevada a cabo por Tomás y Vlastimil Berger.

${ }^{4}$ Posiblemente se utilizaban en los desfiles, tal como ocurrió durante la entrada de Carlos V en Madrid. También en la Armería Real de Madrid se guardan rodelas de madera. Sin embargo, la de Praga es tan excepcional que no puede relacionarse con ninguna conocida. 


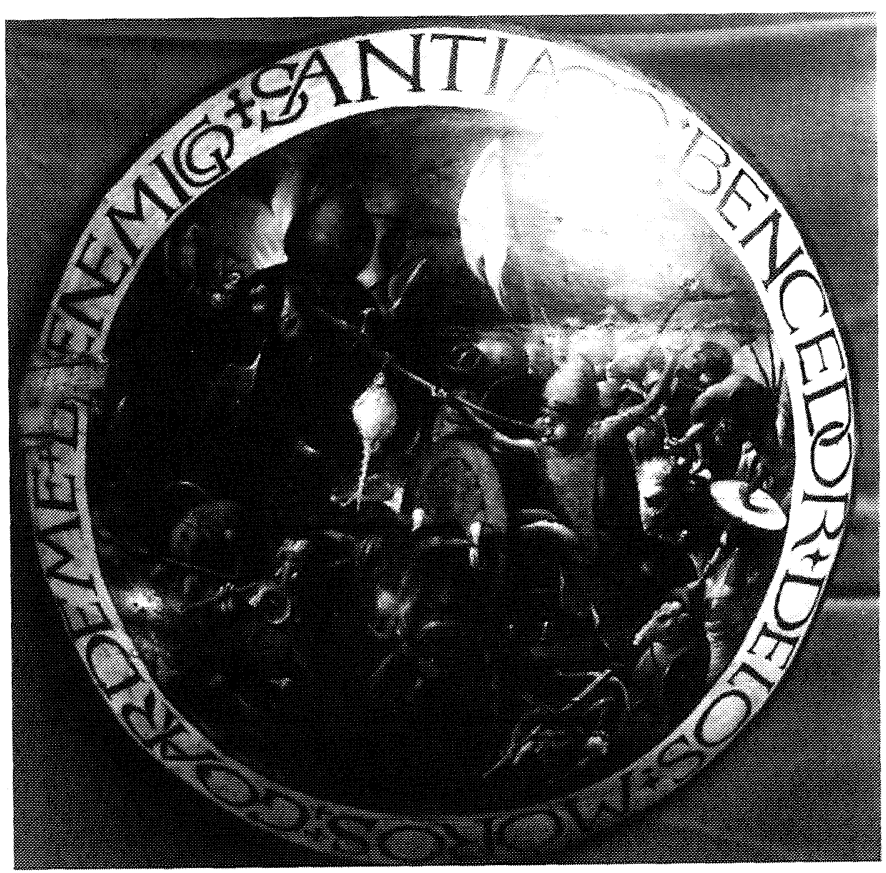

Figura 1. Rodela con el letrero de Santiago. Praga. Museo Nacional.

subasta de las colecciones reales de Praga del día 3 de enero de 1782 que dice en alemán Kleiner Rundschild von Brugel sauber gemalt ${ }^{5}$. La inscripción en castellano, en mayúsculas, que contribuyó un poco el componente pictórico y ayudó a valorar la expresión plástica. El texto dice lo siguiente: + SANTIAGO: BENCEDOR + DE LOS MOROS ++ GOARDEME + D $(E L)$ $E N E M I G O$. Parece que fue agregado a la rodela que data evidentemente del siglo XVI, a principios del siglo XVII, y que - dado el idioma utilizado- fue encargado por un español ${ }^{6}$.

El conjunto de la rodela ofrece varias lecturas. Parece que se van uniendo varios elementos simbólicos. Primero, que dada la oración a Santiago, puede interpretarse como un cuadro apotropaico contra las fuerzas del mal bajo su advocación, es decir, ofrecer protección a su propietario y además, rechazar las fuerzas del mal, probablemente desde el umbral donde se supone fuera colocado. Esta es, en fin, la tradición que viene del tema de la medusa, que aparece con más frecuencia en los escudos conservados.

El mismo motivo de la iconografía fantasmagórica, de los luchadores bizarros, tiene varios niveles, siendo el primario indudablemente un parangón bíblico que habla de la lucha contra el pecado y las fuerzas impuras que amenazan al hombre. Se refiere concretamente a las palabras de San Mateo (18, 6-9), sobre el mal ejemplo a los pequeños, los que creen en Cristo. En la imaginación bosquiana se representa en una composición diagonal una turba

5 Evženie Šnajdrová, Proti silám temnot, Národní museum, 16-XI-31-XII-1994, s. p. Es uno de los textos del tríptico sin paginar que se publicó en aquella oportunidad. Se refiere a ella una información, publicada en la revista del mismo Museo en 1852: Časopis Českého muzea (Revista del Museo Checo), XXVI, 1852, pp. 177 y ss.; «Contribuciones en materias: A la colección de manuscritos: P. Hugo Nettwall, comisario subregional real e imperial... En la pág. 180 leemos que donó además libros publicados en Antwerpia (1564), Francofort (1592), Venecia (1559 y 1532).

${ }_{6}^{6}$ En esto coinciden todos con quienes consulté el tema - Isabel Mateo, Jesús Urrea y A.E. Pérez Sánchez-. 
del mal fatal encabezada por un trompetista montado sobre el asno, con la piedra del molino (otra referencia bíblica). El conjunto tiene una gran cantidad de símbolos que caracteriza el mundo al revés - in malo, al decir de Jarmila Vacková ${ }^{7}$. El extraño caballero metió sus piernas en la piedra en posición invertida; su escudo, un extraño pescado, la raya, pertencece a las profundidades del mar, al cual caerán los tentadores. A la izquierda (desde el punto de vista del cuadro a la derecha, es decir en la parte buena) están mirando desde su propio castillo búhos, los «pequeños», que están saliendo al ataque provistos de ballestas. A su morada pertenece también una extraña mano o mano-pierna. En las murallas de las cuales los buhos están mirando la revista triunfal de animales como asno, toro, ciervo y simio, así como de seres fantásticos bajo la bandera del pescado «impuro», la raya, hay un letrero de wlli burgh, o sea, castillo de buhos, que confirma la interpretación. El buho suele tener un simbolismo sobre todo negativo, pero no puede excluirse también un significado positivo. En caso de admitir el negativo, puede reflejar el refrán flamenco de «auténtico nido de búhos» lo cual podría relacionarse con el nido de avispas, o el salmo 102 (7-8) que habla del búho en las ruinas. Un sentido similar lo tiene la profecía de Isaísas $(34,11)$, según el cual las ruinas de las ciudades destruidas por el castigo del Señor serán ocupadas únicamente por el buho, y pájaros semejantes.

La escena con el ejército bizarro, caracterizado por las armas y los vestidos, absolutamente inesperados, está compuesta con una enorme fantasía e ingenio; cada pequeño espacio de la composición circular está ocupado. A juzgar por la figura con la trompeta larga en el centro del escudo, parece ser una especie de blasfemia del Juicio final. En realidad, la relación del tema del cuadro con la leyenda no está muy clara. Debido a que - a juzgar por la letra- la leyenda es posterior a la pintura, cuyo protagonista es un asno, símbolo de la ignorancia, puede tratarse de una relación bastante arbitraria de los dos componentes ${ }^{8}$.

La excepcional calidad de la pintura que sobresale por encima de cualquier intento de calificarla simplemente de decorativa; es un testimonio de que el comitente podía ser un personaje español importante, quizá relacionado con la Orden de Santiago. Como la obra de Jerónimo Bosco fue muy popular entre los españoles — basta recordar a Diego de Guevara, Fernando de Toledo y Mencía de Mendoza, marquesa de Zenete- y el interés por su obra se mantiene durante largo tiempo (hasta Quevedo habla de ello) ${ }^{9}$, la rodela habrá sido encargada en Flandes, a alguno de los continuadores del Bosco. El mismo Bosco interpretó el tema de Santiago que además, es muy frecuente en la pintura española del siglo XVI. Entre ellos, por ejemplo, Pieter Huys, tiene un Juicio final del año 1554 (Museo de Bellas Artes en Bruselas) de modo que, no se puede excluir la autoría de dicho pintor. También se sugiere, por coincidencias técnicas, la posible relación con Jan Mandyn ${ }^{10}$. El último estudio de las figuras quiere ver el autoretrato del pintor en una de las figuras con cara humana ${ }^{11}$.

7 J. Vacková, en la nota 1. En la exposición colaboró también Jan Royt, pero cuyos comentarios a la iconografía de Santiago «Iconography of the Wooden Shield from the National Museum», pp. 94-96 ignoran por completo las fuentes literarias españolas.

8 A esta interpretación se inclina Isabel Mateo, en una consulta personal.

9 Isabel Mateo Gómez: El Bosco en España. Madrid, 1965, p. 13. El único libro checo sobre Bosco es el de Hana Volavková, Hieronymus Bosch. Praga 1973. Hace diez años se advirtió una cosa importante en la bibliografía bosquiana un dato importante, aunque en un artículo de periódico acerca de la cerámica procedente de Moravia reflejada en los cuadros del maestro flamenco — véase V. Goš— Šefčík, E.: «Moravská keramika na plátnech H. Bosche» (Cerámica morava en los lienzos de H. Bosch). Lidová demokracie, 31-10-1986, domingo, n.․ 44.

${ }_{10}$ J. Vacková, en el tríptico s.p., Tomáł y Vlastimil Berger: «Restorers'Comments», in Hommage, op. cit., p. 93. Completa el estudio el texto del gerente de la Fundación, Robert Vurm, en su artículo Vision Toward the Third Millenium.

11 Eva y Michal Júza, Zdn飞̌k Neubuer, The Shield, p. 101. 
Dado que la rodela viene de las colecciones reales de Praga, puede relacionarse con la mayor probabilidad a la corte de Rodolfo II, en la cual había bastantes españoles, y además una fuerte «facción española», orientada por su catolicismo hacia España ${ }^{12}$. Las futuras investigaciones demostrarán ciertamente la autoría, pues se conocen cada vez más los copistas del Bosco en España, entre ellos Granello ó Graneldo.

En todo caso, se trata de una excelente prueba más de la difusión de la cultura española por estas tierras de la cual estamos aportando testimonios a lo largo del último cuarto del siglo todo un grupo de historiadores, historiadores de literatura $y$, ante todo, historiadores de arte.

PAVEL ŠTĚPÁNEK

\section{LOS RETABLOS DE YUNCLILLOS (TOLEDO), SEGÚN TRAZAS DE JOSEPH DE CHURRIGUERA}

En la villa de Yunclillos, a unos veinte kilómetros al norte de Toledo, la iglesia parroquial de San Andrés conserva providencialmente, tras el incendio de 1972, los tres retablos que ornan la cabecera del templo desde 1700.

El primer interés que suscitó este conjunto retablístico lo fue más en razón de sus pinturas, debidas al madrileño Alonso del Arco (1635-1704), el discípulo de Pereda, de quien es el gran lienzo del retablo mayor representando el martirio en cruz del apóstol, firmado y fechado en $1702^{1}$.

Hasta ahora no se había conjeturado sobre el nombre del artífice del retablo mayor (Fig. 2), magnífica obra del barroco churrigueresco en la provincia de Toledo, junto a los retablos colaterales (Fig. 3), que manifiestan análogo estilo. Apenas una escueta mención en el Catálogo Monumental de la Provincia de Toledo nos advierte que el lienzo está encerrado en un marco dorado con labores de época y «el retablo es grande y barroco, del mismo siglo XVII» 2; obra aún sin estudiar y no por falta de documentación como veremos enseguida. Desde ahora nos es posible traer aquí ciertos datos que han de revelar la autoría y cronología de los tres retablos, cuyo mérito artístico requiere nuestra atención ${ }^{3}$.

Así pues, la primera noticia sobre el retablo es la postura inicial para hacer la obra, que se escritura en Madrid en 14 de marzo de 1699, compareciendo de una parte el «Maestro Pro-

12 Véase P. Stěpánek - E. Bukolská: «Retratos españoles en la colección Lobkowitz en Roudnice», Archivo Español de Arte, XLVI, 1973, pp. 319-334.

1 N. Galindo San Miguel: «Alonso del Arco», A.E.A., 1972, nº 180, pp. 361-362. Se consideran también suyos los dos lienzos de los dos retablos colaterales.

- Conde de Cedillo: Catálogo Monumental de la Provincia de Toledo, Toledo, 1959, p. 409. Aquí se recoge la noticia del autor de la pintura y se alude excepcionalmente al retablo, conocida la fascinación del erudito historiador toledano por el arte renacentista y su silencio de todo lo barroco.

${ }^{3}$ Los libros del Archivo Parroquial de Yunclillos no aportan nada de interés al respecto. En el Libro de Fábrica (1683-1741), sólo en la visita eclesiástica de 1699 un mandato del visitador ordena la conveniencia de acabar el blanqueo de la iglesia pues se «están haciendo retablos para el altar mayor y colaterales y próximos a ponerlos»; y más adelante, en la de 1728, aún estaban los retablos en blanco y por dorar (realmente, se advierte el estilo dieciochesco del dorado).

Agradecemos al párroco D. Rafael Pastor su interés por nuestra investigación y elogiamos su trabajo incansable para la restauración de las imágenes del retablo y otros bienes artísticos de la parroquia. 